\title{
Assessment of Peak Expiratory Flow Rate in Spice Mill Workers - A Cross-Sectional Study
}

\author{
Neha P. Sarokte ${ }^{1}$, Rutika Patil ${ }^{2}$, Ajay Kumar ${ }^{3}$ \\ ${ }^{1}$ B.P.Th, DPO's NETT College of Physiotherapy, Thane, Maharashtra, India. \\ ${ }^{2}$ M.P.Th, Assistant Professor, DPO’s NETT College of Physiotherapy, Thane. \\ ${ }^{3}$ Principal, DPO's NETT College of Physiotherapy, Thane. \\ Corresponding Author: Neha P. Sarokte
}

DOI: https://doi.org/10.52403/ijhsr.20220104

\begin{abstract}
Background: Numerous industries have researched the effects of occupational dust and particles on respiratory function. The continuous exposure to dispersed particles causes respiratory ailments in spice mill workers. Spice dust exposure is linked to a systemic inflammatory response, including respiratory irritation. Spice dust is finely divided solid particles and a form of respirable dust this is the leading cause of occupational disease. Allergies and asthma have been linked to spice mill workers.

Objective: To study the effect of spice dust exposure on expiratory function and to compare the peak expiratory flow rate of spice mill workers and normal adults across age groups and gender

Method: 186 subjects in Mumbai region, 93 spice mill workers and 93 normal adults were selected as per inclusion and exclusion criteria. PEFR was measured in all the participants using a mini Wright peak flow meter.

Result: The statistical analysis showed that there is a significant difference in the peak expiratory flow rates of spice mill workers. However, intergroup analysis between age groups showed that there was not much difference in the PEFR values for the age group 40-50 when compared with normal. The reason could be less number of participants available for the study. Also, the gender-wise comparison showed statistically significant difference in male and female PEFR values.

Conclusion: The present study concluded that peak expiratory flow rate was significantly reduced in spice mill workers when compared to normal adults of same age.
\end{abstract}

Keywords: PEFR, spice mill workers, spice dust, allergies.

\section{INTRODUCTION}

Occupational and environmental lung disorders are serious clinical issues. The effects of occupational dust and particles on employees' respiratory function have been studied in numerous industries. ${ }^{[1]}$

India is a major producer, consumer, and exporter of spices.

Spice workers are exposed to numerous respiratory sensitisers, and spice dust aerosolization has been linked to allergic symptoms of rhino-conjunctivitis and asthma. A large number of people are employed in spice making factories, exposing them to allergens capable of causing allergies and asthma. ${ }^{[2-4]}$

Fraj et al. performed a study on occupational asthma induced by aniseed. PEFR alterations during employment helped to support the diagnosis of occupational asthma. Nonspecific bronchial hyperresponsiveness was detected, possibly due to chronic aniseed exposure. ${ }^{[3]}$ Occupation-related asthma has been connected to spices such as garlic and onion. ${ }^{[5]}$ Dust is finely divided solid particles ranging from 0.1 to 150 microns. Particles larger than 10 microns rapidly 
settle down from the air, yet finer particles float in the air. Particles under 5 microns are breathed straight into the lungs. This inhaled fraction of dust is respirable dust, the leading cause of occupational disease development. ${ }^{[6]}$ Spice particles range in size from 75-1000_m depending on processing $^{[7]}$ Exposure to inhalable spice dust containing garlic and chilli pepper allergens increase the risk of allergic respiratory disease and asthma ${ }^{[5]}$. A study was done in Singapore on 61 spice grinders. Almost half of the subjects studied had upper respiratory tract irritation, including sneezing and runny nose, which they initially noticed after starting spice grinding labour These symptoms affected the skin and upper respiratory tract. $49.2 \%$ of the individuals had sneezing and a runny nose. These symptoms peaked in the first few weeks of working with spices. In half of the subjects, the symptoms were transient and did not recur after the initial few weeks. ${ }^{[8]}$

A Sri Lankan study found that certain symptoms, such as coughing, sneezing, and nasal watering, were present in $95 \%$ of workers at first, but then subsided as a 'tolerance' developed. $^{[9]}$ A recent Singapore research confirmed these findings ${ }^{[8]}$, but neither measured workers' respiratory function. In a study done in Yugoslavia, the work shift workers had a significant frequency of acute respiratory symptoms. These concerns were more common among workers who had a cough, chest tightness, and an itchy or dry throat. MEFV curves were used to assess ventilation capacity. All examined lung function parameters decreased during the work shift in workers with positive skin reactions.. ${ }^{[10]}$

The goal of pulmonary function testing is to determine the existence and severity of respiratory diseases. Diagnostic and therapeutic purposes are served by pulmonary function testing. A pulmonary function test (PFT) is a diagnostic procedure that evaluates the respiratory system. PFTs are typically administered by a respiratory therapist, physiotherapist, pulmonologist, or family physician. A peak flow meter is a relatively simple instrument that is used to determine a patient's 'Peak Expiratory Flow', or 'PEF'. The peak flow meter determines the maximum rate at which you may forcibly exhale following a complete intake.

\section{MATERIALS AND METHODOLOGY}

The present study design was an observational study. A convenient sampling method was used to select participants from the population. Spice mills in Mumbai region were selected and permission from the manager was taken to conduct the study.

A total of willing to participate 186 participants who ranged from 20-50 years were included in the study. The study consisted of 93 spice mill workers exposed to spice dust and 93 normal healthy adult participants. The participants were screened for inclusion and exclusion criteria. Smokers, individuals with a history of major illness like TB, cardiac conditions, ear conditions, eye surgery were excluded from the study. Informed written consent was obtained from each participant. Detailed history in the form of a questionnaire was taken. Participants were explained in detail the purpose and procedure of PEFR assessment. A new mini-wright peak flow meter was used. After a practical demonstration, the subject was asked to perform the test. At least three readings were taken, and the best of the three highest values was recorded.

\section{STATISTICAL ANALYSIS}

The data collected and results were subjected to standard statistical evaluation. Data was collected on a data sheet and encoded for computerised analysis using SPSS version 25.0 for windows. Various statistical measures such as mean, standard deviation, Shapiro- Wilk test for normality and test of significance such as independent t-test was used to analyse available data. A probability value of 0.05 was considered to be statistically significant. 


\section{RESULTS}

Result

All statistical analysis is done by using SPSS 25.0 version.

A total of 186 participants in the age group 20-50 years were assessed. 93 spice mill workers and 93 normal adults of both sexes were analysed for PEFR values. There were 80 males and 13 females spice mill workers. The work experience in the sample population ranged from 1-30 years. Working hours for each individual was 1012hrs. Symptoms such as sneezing, runny nose, and cough were experienced by $63.91 \%$ (62) of workers in the initial few weeks of recruitment, but these symptoms passed off in 3-5 weeks and did not recur in the workers.40.2\% (39) of the workers used a cloth or handkerchief to cover their mouth and nose while working with the spices. No worker reported any symptoms of breathlessness, difficulty in working around the environment with the spices.

Table 1. Mean PEFR of spice mill workers according to gender.

\begin{tabular}{|l|l|l|}
\hline Gender & Frequency & Mean PEFR \\
\hline Male & 80 & $349.38 \pm 96.95$ \\
\hline Female & 13 & $315.38 \pm 80.06$ \\
\hline
\end{tabular}

Table 2. Comparison of mean PERF of a spice mill worker and normal adults

\begin{tabular}{|l|l|l|}
\hline Variable & N & Mean \\
\hline Spice mill workers & 93 & $155.79 \pm 11.90$ \\
\hline Normal adult & 93 & $430.10 \pm 77.02$ \\
\hline
\end{tabular}

The Shapiro-Wilk test was done to assess whether the data is normally distributed. The test showed that the data was not normally distributed, only the height variable was had a significant outcome.

Hence, a non-parametric independent t-test was performed to compare the data.

Table 3. Comparison of PEFR between Spice mill workers and normal adults using t-test
\begin{tabular}{|l|l|l|l|}
\hline Variable & Mean Difference & Std. Error Difference & df \\
\hline Spice mill workers & -274.3118 & 8.08105 & 184 \\
\hline Normal adults & -274.3118 & 8.08105 & 96.393 \\
\hline
\end{tabular}

Table 4. Comparison of mean PERF of spice mill workers and normal adult workers according to age groups

\begin{tabular}{|l|l|l|l|}
\hline Age group & Mean PERF of Spice mill workers & Mean PERF of Normal & p value \\
\hline $20-30$ & $352.22 \pm 92.90$ & $460.90 \pm 84.62$ & 0.001 \\
\hline $31-40$ & $340.78 \pm 92.16$ & $421.05 \pm 69.39$ & 0.001 \\
\hline $41-50$ & $325.00 \pm 120.76$ & $378.94 \pm 41.88$ & 0.087 not significant \\
\hline
\end{tabular}

Inference: $p$ value $<0.001$ statistically significant

Table 5. Comparison of mean PERF of spice mill worker and normal adult worker according to gender

\begin{tabular}{|l|l|l|l|}
\hline Age group & Mean PERF of Spice mill workers & Mean PERF of Normal adults & p value \\
\hline Male & $349.37 \pm 96.95$ & $465.18 \pm 72.56$ & $<0.000$ \\
\hline Female & $315.38 \pm 80.06$ & $380.36 \pm 51.53$ & $<0.003$ \\
\hline
\end{tabular}

Inference: $p$ value $<0.05$ statistically significant

\section{DISCUSSION}

The study involved 186 male and female participants aged 20-50 years. Out of which 93 participants were workers of a spice mill, and the other 93 participants were normal adult healthy individuals.

Our study is different in this regard from others that other studies did research on the occupational hazard of spice on the workers and did a survey to check the presence of immunologic and nonimmunologic allergic reactions to spices. ${ }^{[11]}$ In India very few studies are done to check the respiratory functioning among the spice mill workers.
This study aimed to assess the peak expiratory flow rate in spice mill workers, who are exposed to inhalable spice powder generated during the process as spice contains various substances that lead to allergic reactions of the respiratory system and skin. ${ }^{[2]}$ Studies have shown that people who work in spice farming and the food industry are more prone to respiratory and other diseases as they are exposed to a considerable amount of spice dust. ${ }^{[11]}$ In this study, it was observed that the majority of the workers in the spice mill belong to the age group 20 -30 years (48.39\%) and 30 40 years (40.86\%), whereas the least 
recruited age group population seen was between $40-50$ years $(10.75 \%)$ hence did not have a significant difference in the PEFR when compared with the normal adults of same age group.

The gender-wise distribution of the workers highlighted that $86 \%$ were male workers and only $14 \%$ were female workers. As a result, there was a significant difference in the mean PEFR of male workers compared to female workers. Noor et al. (2002) also found in their study that male spice factory workers exhibited lower FEV1/FVC\% compared to the control group, which suggested a possible obstructive problem in their lungs. ${ }^{[12]}$

O.Y.Chan et al. found in their study dust levels ranged from 0.03 to $0.82 \mathrm{mg} / \mathrm{m} 3$, with a mean of $0.15 \mathrm{mg} / \mathrm{m} 3$. The average respirable dust fraction was $45.9 \%$. ${ }^{[8]}$ Our study revealed that almost all the workers were exposed to spice dust for a duration of 10-12 hrs each day for six days of a week. This led to prolonged exposure to the potentially harmful inhalable spice dust.

Sudha Babel et al. reported symptoms of upper respiratory tract irritation, and after a variable amount of time, each worker developed a tolerance and was symptom-free while not at work. ${ }^{[13]}$ In our study, spice workers were asked about symptoms of upper respiratory tracts. It was observed that $63.91 \%$ of workers had these symptoms during the initial weeks of their job but these symptoms subsided in a few weeks and did not recur. According to Jones, chilli powder is irritating dust. Irritating gases including ammonia, sulphur dioxide, and chlorine appear to be similar in their action on the respiratory mucosa. ${ }^{[14]}$ More studies are being done that shows similar findings. All of these may promote airway constriction and lower PEFR in spice mill workers.

Awareness can be spread among the spice mill workers regarding the use of proper protective equipment to be used while working and the possible harmful effect of prolonged exposure to spice dust.

\section{Limitations}

1) The study was performed over small sample size.

2) Samples were collected only from Mumbai regions.

3) No tests are done to check the inspiratory functions.

\section{CONCLUSION}

There is a significant difference in spice mill workers' peak expiratory flow rate due to prolonged exposure to inhalable spice dust while working in the spice mill factory.

\section{ACKNOWLEDGEMENTS}

I express my deep sense of gratitude and sincere thanks to our respected sir Dr. Ajay Kumar and Guide Dr. Rutika Shivdikar who immensely helped me with their sincere guidance, untiring cooperation, endless inspiration and valuable advice during the course of the study. I also take this opportunity to thank the teaching and non-teaching staff, my friends and colleagues for their support.

\section{Conflict of Interest: None}

\section{Source of Funding: None}

\section{Ethical Approval: Approved}

\section{REFERENCES}

1. Seaman DM, Meyer CA, Kanne JP. Occupational and environmental lung disease. Clin Chest Med. 2015;36(2):24968.

2. Van der Walt A, Lopata A, L, Nieuwenhuizen N, E, Jeebhay M, F. WorkRelated Allergy and Asthma in Spice Mill Workers - The Impact of Processing Dried Spices on IgE Reactivity Patterns. Int Arch Allergy Immunol. 2010;152:271-278.

3. Fraj J, Lezaun A, Colás C, Duce F, Domínguez MA, Alonso MD. Occupational asthma induced by aniseed. Allergy. 1996;51(5):337-9.

4. Van der Walt A, Baatjies R, Singh $T$, Jeebhay MF. Environmental factors associated with baseline and serial changes in fractional exhaled nitric oxide (FeNO) in spice mill workers. Occupational 
Environmental Medicine. 2016;73(9):61420.

5. Van der Walt A, Singh T, Baatjies R, et al. Work-related allergic respiratory disease and asthma in spice mill workers is associated with inhalant chilli pepper and garlic exposures Occupational and Environmental Medicine .2013;70:446-452.

6. K. Park. Textbook of preventive and social medicine. $23^{\text {rd }}$ edition,2015 CHP 15 pp 805.

7. Tangirala, A.D.S.; Charithkumar, K.; Goswami, T.K. Modeling of size reduction, particle size analysis and flow characterisation of spice powders ground in hammer and pin mills. Int. J. Res. Eng. Technol. 2014;3,296-309.

8. Chan OY, Lee CS, Tan KT, Thirumoorthy T. Health problems among spice grinders. J Soc Occup Med. 1990;40(3):111-5.

9. K. N. Lankatilake, C. G. Uragoda. Respiratory function in chilli grinders. Occupational Medicine. 1993;43(3):139_ 142.

10. Zuskin E, Kanceljak B, Skuric Z, Pokrajac D, Schachter EN, Witek TJ, Maayani S. Immunological and respiratory findings in spice-factory workers. Environ Research.1988;47(1):95-108.

11. Upadhyay E, Mohammad AlMass AA, Dasgupta N, Rahman S, Kim J, Datta M. Assessment of Occupational Health Hazards Due to Particulate Matter Originated from Spices. International Journal of Environmental Research and Public Health. 2019; 16(9):1519.

12. Noor, Hamdan and Sansi, Wahidah and Othman, Zolkepli and Mohamad, Faridah. Effects of spice dust on lung functions and respiratory symptoms in spice factory workers in Selangor. Pertanika Journal of Tropical Agriculture Science. 2000;23 (2).

13. Babel, Sudha and Rajvanshi, Rupali. Occupational health hazards faced by the spice grinding workers. Asian Journal of Home Science. 2013;8 (2): 518-521.

14. Jones, A.T. Noxious gases and fumes. Proc. Roy. Soc. Med. 1952;45(9): 609-610

15. Uragoda CG. Symptoms among chilli grinders. British Journal of Industrial Medicine. 1967;24(2):162-164.

16. Patil SN, Somade PM, Joshi AG. Pulmonary function tests in sugar factory workers of Western Maharashtra (India). Journal of Basic and Clinical Physiology and Pharmacology. 2008;19(2):159-66

17. Shamssain MH. Respiratory symptoms and pulmonary function in flour processing workers in the baking industry. American Journal of Industrial Medicine. (1995). 27(3):359-65

18. Shamssain MH. Pulmonary function and symptoms in workers exposed to wood dust. Thorax. 1992;47(2):84-7

19. Kamini D, Nikam, Munira A. HIrkani. Effects of Chalk dust on Peak Expiratory Flow Rate in School Teachers. International Journal of Medical and Health Sciences. 2013;2(4):407-409

How to cite this article: Sarokte NP, Patil R, Kumar A. Assessment of peak expiratory flow rate in spice mill workers - a cross-sectional study. Int J Health Sci Res. 2022; 12(1): 23-27. DOI: https://doi.org/10.52403/ijhsr.20220104 